\title{
Prevalence and risk assessment for sexually transmitted infections in pregnant women and female sex workers in Mali: is syndromic approach suitable for screening?
}

\begin{abstract}
Introduction
The analysis of local factors and the determination of most appropriate risk assessment are essential for the development of clinical algorithms for the management of STIs. ${ }^{1-4}$ In Mali little is known about the prevalence and risk assessment for reproductive tract infections in women. This study aimed to document the prevalence and risk factors for cervical and vaginal infections among a high and a low risk group and to assess the diagnostic value of factors associated with these infections.
\end{abstract}

\section{Materials and methods}

In June 1997, cross sectional surveys were conducted among pregnant women $(\mathrm{n}=549)$ in Bamako and in sex workers in Bamako $(n=191)$ and Sikasso $(n=93)$. Data on sociodemographic characteristics, sexual behaviour, and clinical signs were recorded. After clinical examinations, blood and genital specimens were collected. Women taking any antibiotics and who did not consent were excluded. The presence of Trichomonas vaginalis, yeast, clue cells, polynuclear cells, and leucocytes was determined by direct microscopic examination of a wet mount and after Gram coloration.

Neisseria gonorrhoeae was identified by culture on modified Thayer-Martin medium. Chlamydia trachomatis antigen was detected track II EIA (Syva, France). Syphilis was diagnosed by RPR test (Becton Dickinson) and TPHA (Fujirebio, Japan). HIV testing was performed using a rapid test for screening (Capillus HIV-1/2, Cambridge Diagnostic, Ireland) and a Line immunoassay for confirmation (Innolia HIV-1/2, Innogenetics, Belgium). We defined cervical infections as the presence of $N$ gonorrhoeae and/or $C$ trachomatis antigen; vaginal infections by the presence of $T$ vaginalis and/or $C$ albicans and/or clue cells. EPI-INFO was used for data in endocervical specimen using the Micro-

analysis. Association between various factors and cervical or vaginal infections was evaluated by the odds ratio and its $95 \%$ confidence intervals.

\section{Results}

The mean age of pregnant women was 24 years, $538(98 \%)$ were Malian and 260 $(47 \%)$ had a history of STIs. Sex workers in Bamako had a mean age of 27 years and a mean duration of prostitution of 4.2 years; $151(79 \%)$ always or sometimes used condoms, and $124(65 \%)$ had a history of STIs. Sex workers in Sikasso had a mean age of 29 years, and a mean duration of prostitution of 4.6 years; $42(45 \%)$ always or sometimes used condoms and $72(77 \%)$ had a history of STIs. Table 1 shows the STI prevalence in the study population.

Cervical infections were associated with younger age in both groups; pregnant women aged $\leqslant 25$ years (OR 2.67, 95\% CI 1.02 7.38 ) and sex workers aged $\leqslant 21$ years (OR $3.50,95 \%$ CI 1.41-8.78) were infected compared with older women. In addition, sex workers who had more than 10 clients per week had cervical infections (OR 3.04, 95\% CI 1.23-7.61).

In pregnant woman, lower abdominal pain was the only sign associated with cervical infections (OR 2.45, 95\% CI 0.18-0.92). In this group, vaginal itching was associated with vaginal infections (OR 1.59, 95\% CI 1.09-2.30).

Among sex workers, no condom use (OR $2.99,95 \%$ CI 1.29-7.10) and the length (> 3 years) of prostitution (OR 2.16, 95\% CI 1.12-4.18) were associated with vaginal infections.

Abnormal clinical signs were rare, more than $50 \%$ of infected women were asymptomatic. The sensitivities of variables associated with cervical or vaginal infections were above $70 \%$; their specificities were very low $(<50 \%)$. Owing to the low prevalence of STI

Table 1 Prevalence of infections among pregnant women and sex workers in Mali

\begin{tabular}{|c|c|c|c|}
\hline \multirow[b]{2}{*}{ Infections } & \multirow{2}{*}{$\begin{array}{l}\text { Pregnant women } \\
\text { Bamako } \\
(n=549) \\
\text { No (\%) }\end{array}$} & \multicolumn{2}{|c|}{ Sex workers } \\
\hline & & $\begin{array}{l}\text { Bamako } \\
(n=191) \\
\text { No (\%) }\end{array}$ & $\begin{array}{l}\text { Sikasso } \\
(n=93) \\
\text { No (\%) }\end{array}$ \\
\hline Gonorrhoea & $6(1)$ & $8(4)$ & $7(8)$ \\
\hline Chlamydia & $29(5)$ & $8(4)$ & $5(5)$ \\
\hline Trichomoniasis & $119(22)$ & $62(33)$ & $13(14)$ \\
\hline Candida & $216(39)$ & $33(17)$ & $68(73)$ \\
\hline Clue cells & $104(19)$ & $46(24)$ & $39(42)$ \\
\hline Syphilis (RPR+TPHA) & $11(2)$ & $14(7)$ & $4(4)$ \\
\hline HIV & $15(3)$ & $58(30)$ & $10(11)$ \\
\hline \multicolumn{4}{|l|}{ Cervical infections ( $N$ gonorrhoeae and/or } \\
\hline C trachomatis) & $34(6)$ & $16(8)$ & $10(11)$ \\
\hline \multicolumn{4}{|l|}{ Vaginal infections (Trichomonas vaginalis and/or } \\
\hline Candida albicans and/or clue cells) & $339(62)$ & $109(57)$ & $79(85)$ \\
\hline
\end{tabular}

in this population, the PPV were not greater than $10 \%$ in detecting cervical infections.

\section{Discussion}

Vaginal and cervical infections were common in asymptomatic pregnant women and sex workers in Mali. The overall prevalence of cervical infections $(9 \%)$ in sex workers was relatively lower compared with what has been reported in the same population groups in other west African countries, such as in Côte d'Ivoire $35 \%{ }^{5}$ and Senegal 25\%. ${ }^{6}$ This may be explained by the fact that all prostitutes enrolled in the study were also included in the health project of DANAYASO; where health education and condom promotion are provided. Regional difference was observed in relation to HIV prevalence among sex workers in particular. The reason for this regional difference is not clear, since our study did not show any major difference in the characteristics of sex workers in terms of age, length of prostitution, and sexual behaviour. Nevertheless, the HIV epidemic might be more recent in Sikasso, a rural area, resulting in a lower number of contacts with infected individuals.

Factors, which elsewhere have been associated with cervical or vaginal infections, were not found to be so in our study, especially among pregnant women. Our data indicate that low prevalence of STIs and lack of symptoms among infected women, even in the high risk group, are real constraints in the development of a suitable tool for STI screening. These findings suggest that syndromic approaches may not be suitable for screening cervical or vaginal infections in this setting. Further studies are needed to develop feasible screening strategies for asymptomatic patients in developing countries.

We are grateful to the Ministry of Health, the National AIDS/STD Committee, the Regional director of Health in Sikasso, the staff of the six districts health centres in Bamako, and the staff of the INRSP laboratory in Bamako, the staff of DANAYASO, who assisted with logistical support in the field work and for their kind cooperation.

We are grateful to Dr Lieve Franssen (European We are grateful to Dr Lieve Franssen (European
Union) for promoting and supporting the regional project in West Africa.

This study was sponsored by the European Union DG VIII/8 G1 (contract no 7 ACP RPR28).

Contributors: ED, principal investigator for the regional project, was responsible for the study design, supervision, and the preparation of the manuscript; CMK was responsible of study design, data analysis, fieldwork, and the preparation of the manuscript; YIM and ZD were responsible for the supervision of the study sites; IN was the principal investigator of the regional project and the study investigator of the regional project and the study design; HD was responsible of the statistical analysis and the manuscript preparation; EM and PD were responsible of the laboratory testing; FB was laboratory scientist, in addition to the laboratory testing on the study sites, was responsible of the subject recruitment; SG was a senior clinician at the DANAYASO centre and responsible of FSW contact. 
C MULANGA-KABEYA

E MOREL

D PATREL

E DELAPORTE

Laboratoire Rétrovirus, Institut de Recherche pour le Développement, (IRD/ex ORSTOM), Montpellier, France

\section{F BOUGOUDOGO}

Institut National de Recherche en Santé Publique (INRSP), Bamako, Mali

Y I MAIGA

Z DIAWARA

Programme Nationale de Lutte contre le SIDA, Bamako, Mali

I NDOYE

Institut d'Hygiène Sociale (IHS), Dakar Sénégal
S GARANGUÉ
Centre DANAYASO, Bamako, Mali

D HENZEL

Institut de Médecine et d'Epidémiologie Africaines, CHU Bichat-C Bernard, Paris, France

Correspondence to: C Mulanga-Kabeya,

Laboratoire Rétrovirus, Institut de Recherche pour le Développement (IRD/ex ORSTOM), $911 \mathrm{Av}$ Agropolis, 34032 Montpellier, France.

1 Mayaud P, Grosskurth H, Changalucha J, et al. Risk assessment and other screening option for gonorrhoea and chlamydial infections in women attending rural Tanzanian antenatal clinics. Bull World Health Organ 1995;73:62130 .

2 Van Dam J, Becker KM, Ndowa F, Islam MQ. management: where do we go from here? Sex Transm Inf 1998;74(suppl 1):S175-8.

3 Behets F, Williams Y, Brathwaite A, et al. Management of vaginal discharge in women treated at a Jamaican sexually transmitted diseases clinic: use of diagnostic algorithms versus laboratory testing. Clin Infect Dis 1995;21:1450-5.

4 Bourgeois A, Henzel D, Dibanga G, et al. Clinical algorithms for the screening of pregnant women for STDs in Libreville, Gabon: which alternatives? Sex Transm Inf 1998;74:35-9.

5 Diallo MO, Ghys PD, Vuylsteke B, et al. EvaluDialo $\mathrm{MO}$, Ghys $\mathrm{PD}$, Vuylsteke $\mathrm{B}, \mathrm{ct}$ al. Evaluation of simple diagnostic algorithms for Neisseria gonorrhoeae and Chlamydia trachomati Abidjan, Côte d'Ivoire. Sex Transm Inf 1998; 74(suppl 1):S106-11.

6 74(suppl 1):S106-11. syndromique pour la prise en charge des femmes ayant une MST est-elle une solution? Résultats de l'expérience sénégalaise. Xème Conférence Internationale sur le SIDA et les MST en Afrique, Abidjan, Côte d'Ivoire, 1997, Abstract No B123. 


\section{Prevalence of reproductive tract infections in family planning clients in Trabzon, Turkey}

\section{Introduction}

The study took place at two family planning (FP) clinics in Trabzon, Turkey where 410 female patients aged 16-57 (mean 31.8 (SD 7.1)) attending the two FP clinics in October and December 1997 were tested for reproductive tract infections (RTIs).

\section{Methods}

After the administration of a baseline survey, pelvic examination was conducted for each woman and appropriate samples were taken for microscopic examination, culture, and serological analyses. Bacterial vaginosis was diagnosed according to Nugent's scoring system. ${ }^{1}$ Cervical antigen detection (Cellabs Chlamydia Celisa, Australia) and cell culture was used for the diagnosis of Chlamydia trachomatis. Wet mount preparations were evaluated within 15 minutes for the detection of motile trichomonads and culture and examination results were used for the diagnosis of vulvovaginal candidiasis (VVC) together with patient symptoms. Serological tests were used for anti-HIV antibody (Vironostika; Organon Teknika, Netherlands), hepatitis B surface antigen (Hepanostika; Organon Teknika, Netherlands), RPR (RPRnostikon II; Organon Teknika, Netherlands), and antigonorrhoea antibodies (IgG and IgM) (Alfa Biotech Gonorrhea Agglutinotest Tetrakit, Italy). Neisseria gonorrhoeae was also assessed by Gram staining of cervical smears. The $\chi^{2}$ test was used for the analyses of associations between different variables.

\section{Results}

Of all 410 women, $99.5 \%$ were married and monogamous, $58.3 \%$ had five or fewer years of schooling, $88.3 \%$ were housewives, and $62.2 \%$ had three or more pregnancies. The most prevalent infection was found to be BV (28.2\%), followed by $C$ trachomatis $(12.0 \%)$, VVC (11.3\%), $N$ gonorrhoeae (4.5\%), hepatitis B $(2.0 \%)$, Trichomonas vaginalis $(2.0 \%)$ and syphilis $(0.25 \%)$ respectively. No HIV seropositivity was detected. Overall, $46.1 \%$ of all women had at least one RTI and $14.2 \%$ had multiple infections. Reproductive tract infections were found to be significantly more prevalent in women aged 25 or over $(p=0.03)$ (table 1). Although educational level, place of

Table 1 Results of analyses for associations between different variables and diagnosis of reproductive tract infections $(R T I s)^{*}$

\begin{tabular}{|c|c|c|c|c|c|}
\hline Variables & No & $\begin{array}{l}\text { \% of women } \\
\text { diagnosed with RTIs }\end{array}$ & $\begin{array}{l}\text { Odds } \\
\text { ratio }\end{array}$ & $\begin{array}{l}\text { Confidence } \\
\text { interval ( } 95 \% \text { ) }\end{array}$ & $p$ Value \\
\hline \multicolumn{6}{|l|}{ Age } \\
\hline $16-24$ & 68 & 33.8 & & & \\
\hline 25 and over & 342 & 48.5 & 0.54 & $0.30-0.97$ & 0.03 \\
\hline \multicolumn{6}{|l|}{ Educational level† } \\
\hline 5 years or less & 301 & 45.5 & & & \\
\hline 6 years or more & 109 & 47.7 & 0.92 & $0.57-1.46$ & 0.69 \\
\hline \multicolumn{6}{|l|}{ Place of living } \\
\hline Urban (city centre) & 301 & 46.5 & & & \\
\hline Semirural or rural & 109 & 45.0 & 1.06 & $0.67-1.70$ & 0.78 \\
\hline \multicolumn{6}{|l|}{ Working statust } \\
\hline Housewife & 362 & 45.9 & & & \\
\hline Paid work outside home & 48 & 47.9 & 0.92 & $0.48-1.76$ & 0.79 \\
\hline \multicolumn{6}{|l|}{ Vaginal discharget } \\
\hline Yes & 275 & 46.9 & & & \\
\hline No & 134 & 44.0 & 1.12 & $0.72-1.75$ & 0.58 \\
\hline \multicolumn{6}{|l|}{ Dysuria } \\
\hline Yes & 75 & 58.7 & & & \\
\hline No & 334 & 43.1 & 1.87 & $1.09-3.23$ & 0.01 \\
\hline \multicolumn{6}{|l|}{ Lower abdominal pain $\dagger$} \\
\hline Yes & 160 & 48.8 & & & \\
\hline No & 249 & 44.2 & 1.20 & $0.79-1.83$ & 0.37 \\
\hline \multicolumn{6}{|l|}{ Itching in the genital area } \\
\hline Yes & 107 & 53.3 & & & \\
\hline No & 302 & 43.4 & 1.49 & $0.93-2.38$ & 0.08 \\
\hline \multicolumn{6}{|c|}{ History of STD symptoms in the husband (past 1 year) } \\
\hline Yes & 29 & 69.0 & & & \\
\hline & 380 & 44.2 & 2.80 & $1.17-6.90$ & 0.01 \\
\hline \multicolumn{6}{|c|}{ Previous treatment for genital infections $\dagger$} \\
\hline Yes & 175 & 50.3 & & & \\
\hline No & 234 & 42.7 & 1.36 & $0.89-2.06$ & 0.13 \\
\hline
\end{tabular}

${ }^{\star}$ Reproductive tract infection is defined as having at least one of the following: $T$ vaginalis, $N$ gonorrhoeae, $C$ trachomatis, syphilis, hepatitis B, HIV, bacterial vaginosis, or vulvovaginal candidiasis.

†No association with RTIs. living (rural or urban) or working status of women were not found to be associated with RTIs ( $p=0.05$ ), having complaints of dysuria and history of sexually transmitted disease (STD) symptoms in the husband were also significantly associated with the diagnosis of RTIs $(\mathrm{p}=0.01)$.

\section{Comment}

RTIs are prevalent among married monogamous women of middle age who are classically defined as the "low risk group." 2 These results are similar to other local studies conducted in Turkey. ${ }^{34}$ Although the nonsexually transmitted RTIs (that is, BV and VVC) account for the majority of the infections, results suggest that chlamydia infections, which are usually ignored for diagnosis and treatment can also be important among other RTIs. The traditional risk factors for STDs such as young age and low socioeconomic status (as indicated by low level of education, semi/rural residence, and not having paid work) were not replicated in this study. It can be inferred that RTIs in developing countries can have different patterns and risk markers/factors.

NURIYE NALAN SAHIN HODOGLUGIL

Hacettepe University Medical Faculty, Public Health Department, Ankara, Turkey

BEHIRE ÖZEK

FHPIEGO (A fohns Hopkins Program for

International Education in Reproductive

Health) Country Representative, Ankara, Turkey

MUNEVVER BERTAN

Hacettepe University Medical Faculty, Public

Health Department, Ankara, Turkey

Correspondence to: Dr N Nalan Sahin

Hodoglugil, Hacettepe University Medical Faculty, Public Health Department, Sihhiye, 06100 Ankara, Turkey.

1 Nugent RP, Krohn MA, Hillier SL. Reliability of diagnosing bacterial vaginosis is improved by a standardized method of gram stain interpretation. F Clin Microbiol 1991;29:297-301.

2 Wasserheit JN, Holmes KK. Reproductive tract infections: challenges for international health policy, programs and research In Germain A, policy, programs and research. In: Germain A Holmes KK, Piot P, Wasserheit JN, eds. Reproductive tract infections: global impact and prioritie for women's reproductive health. Internationa Press, 1992: 7-33.

3 Agacfidan A, Chow JM, Pashazade $\mathrm{H}$, et al. Screening of sex workers in Turkey for Chlamydia trachomatis. Sex Transm Dis 1997; 24(10):573-5.

4 Ronsmans C, Bulut A, Yolsal N, et al. Clinical algorithms for the screening of Chlamydia trachomatis in Turkish women. Genitourin Med 1996;72:182-6. 